\title{
Simultaneous electrochemical sensing of dihydroxy benzene isomers at cost- effective allura red polymeric film modified glassy carbon electrode
}

\author{
Pattan-Siddappa Ganesh ${ }^{1}$, Ganesh Shimoga', Seok-Han Lee ${ }^{1}$, Sang-Youn Kim ${ }^{1 *}$ and Eno E. Ebenso ${ }^{2^{*}}$
}

\begin{abstract}
Background: A simple and simultaneous electrochemical sensing platform was fabricated by electropolymerization of allura red on glassy carbon electrode (GCE) for the interference-free detection of dihydroxy benzene isomers.

Methods: The modified working electrode was characterized by electrochemical and field emission scanning electron microscopy methods. The modified electrode showed excellent electrocatalytic activity for the electrooxidation of catechol $(\mathrm{CC})$ and hydroquinone $(\mathrm{HQ})$ at physiological pH of 7.4 by cyclic voltammetric $(\mathrm{CV})$ and differential pulse voltammetric (DPV) techniques.

Results: The effective split in the overlapped oxidation signal of CC and HQ was achieved in a binary mixture with peak to peak separation of $0.102 \mathrm{~V}$ and $0.103 \mathrm{~V}$ by $\mathrm{CV}$ and DPV techniques. The electrode kinetics was found to be adsorption-controlled. The oxidation potential directly depends on the $\mathrm{pH}$ of the buffer solution, and it witnessed the transfer of equal number of protons and electrons in the redox phenomenon.

Conclusions: The limit of detection (LOD) for CC and HQ was calculated to be $0.126 \mu \mathrm{M}$ and $0.132 \mu \mathrm{M}$ in the linear range of 0 to $80.0 \mu \mathrm{M}$ and 0 to $110.0 \mu \mathrm{M}$, respectively, by ultra-sensitive DPV technique. The practical applicability of the proposed sensor was evaluated for tap water sample analysis, and good recovery rates were observed.
\end{abstract}

Keywords: Catechol, Hydroquinone, Cyclic voltammetry, Electrooxidation, Limit of detection

\section{Background}

Over the past few decades, the rapid progress of science and technology to fulfil the desire of human beings led to many advancement as well as became a threat to environment (Xia et al. 2021; Ali \& Jain, 2004; Gupta et al. 2009; Asfaram et al. 2015; Ali et al. 2013). As the proverb says "the science of today is the technology of tomorrow," many industries were established to make the best use of pure science in the

\footnotetext{
* Correspondence: sykim@koreatech.ac.kr; eno.ebenso@gmail.com 'Interaction Laboratory, Future Convergence Engineering, Advanced Technology Research Center, Korea University of Technology and Education, Cheonan-si, Chungcheongnam-do 31253, Republic of Korea ${ }^{2}$ Institute of Nanotechnology and Water Sustainability, College of Science, Engineering and Technology, University of South Africa, Johannesburg 1709, South Africa
}

production of applied commercial products (Steven, 1998; Goyal et al. 2009a, 2009b; Dehghani et al. 2016; Gupta et al. 14a, 2014b, 2014c; Goyal et al. 2009a, 2009b; Ghaedi et al. chemical engineering, lubricant refining, metallurgy, energy storage, light industry, petroleum products, the environment, drug, environmental safety and the military division (Gavrilescu \& Chisti, 2005; Schmid et al. 2002; Goyal et al. 2005; Gupta et al. 2015c; Karthikeyan et al. 2012; Robati et al. 2016; Saravanan et al. 2015b). However, the waste effluent 
coming out as a side product in all the manufacturing industries may cause big impact on environmental pollution and can become toxic to human beings and aquatic creatures (Ahammad et al. 2011). Therefore, the quantification of the toxic molecules in the waste sample is of prime concern (Buleandra et al. 2014; Gupta et al. 2015a, 2015b, 2015c; Gupta et al. 2014a, 2014b, 2014c; Gupta et al. 2012; Saravanan et al. 2013a, 2013b, 2013c). Most phenolic moieties are toxic, and they are the basic feed stocks of the manufacturing industries (Wang \& Hasebe, 2011; Saravanan et al. 2013a, 2013b, 2013c; Saravanan et al. 2015b). Catechol (CC) and hydroquinone (HQ) are the isomers of dihydroxy benzene, which are widely used in paint, leather, pharmaceutical, pesticide, cosmetic and plastic industries, and obviously, the effluent from these manufacturing industries contain traces of $\mathrm{CC}$ and $\mathrm{HQ}$ which in turn become toxic to human and animals (Wang et al. 2007a, 2007b, 2007c; Kumar et al. 2017). Due to this these, molecules were recognized as an ecological hazard ( $\mathrm{He}$ et al. 2014). The drawback of using traditional spectroscopic methods for their determination is tedious and not consistent (Chao \& Suatoni, 1982; Nagaraja et al. 2001; Sun et al. 2000; Mesa \& Mateos, 2007).

The electrochemical sensors are very widely employed in food safety, dye, pharmaceutical and environmental fields due to their rapid, simple operation, quick and high sensitivity in the result (Saravanan et al. 2013a, 2013b, 2013c; Govindhan et al. 2014; Gupta et al. 2013; Yola et al. 2014; Srivastava et al. 1996; Maleh et al. 2015). Since dihydroxy benzene isomers are electroactive, electrochemical way is the most accessible method for electroanalysis (Li et al. 2014). However, the fewer sensitivity, slow electron transport and contamination of the oxidation signal by adsorption of products limit the recognition of these isomers by the bare glassy carbon electrode (GCE) (Shen et al. 2017). Hence, recently various modification procedures were reported to enhance the performance of the GCE to quantify the analytes of interest, such as eosin Y (He et al. 2014), poly (diallyl dimethylammonium chloride) (Song et al. 2015), poly (dopamine) (Zheng et al. 2013), poly (glycine) (Wang et al. 2007b), poly (phenylalanine) (Wang et al. 2006), poly (methionine) (Chandrashekar et al. 2019), cassava starch- $\mathrm{Fe}_{3} \mathrm{O}_{4}$ (Mulyasuryani et al. 2019), poly (3,4-ethylenedioxythiophene) (Bottari et al. 2019), poly (L-serine) (Hung et al. 2020), ATNA/Nafion/GCE (El-Shishtawy et al. 2020), 4carboxybenzenediazonium (Phal et al. 2020), polyaniline-FSG (Minta et al. 2020), PVP-GR/GCE (He et al. 2020), PB/ZrO $\mathrm{fCNTs} / \mathrm{GC}$ ) (Jerez-Masaquiza et al. 2020), Azure Apoly(methacrylic acid)/GCE (Watanabe et al. 2020), pyridine2-sulfonic acid/GCE (Xiao et al. 2020), poly(brilliant blue) (Ganesh et al. 2015), and poly(muroxide) (Kumar et al. 2019).

Allura red AC (ALR) (see Scheme S1, supplementary file) is one of the azo dyes extensively used in the colouring confectionery, soft and alcoholic drinks, ice cream, candy and bakery products (Pliuta et al. 2020). This simple azo dye can be efficiently used to modify the bare GCE by electropolymerization technique. We followed a protocol proposed by Mansour et al. for the electropolymerization of allura red AC on GCE, which they employed for the flow injection analysis determination of $\mathrm{HQ}$ and $\mathrm{CC}$ using a two-line flow injection manifold with a single-sensor/double-pulse amperometric detection (Mansour et al. 2019). In this study, we reported the modification procedure for the GCE by simple electropolymerization of ALR by cyclic voltammetric $(\mathrm{CV})$ technique in a basic supporting electrolyte solution. The fabricated ALR glassy carbon electrode (ALR/GCE) showed electrocatalytic activity in the discrimination of overlapped signals of $\mathrm{CC}$ and $\mathrm{HQ}$ in a binary mixture which is practically not possible at bare GCE. The ALR/GCE was electrochemically characterized; the effect of scan rate showed adsorption kinetics at ALR/GCE. Mechanism of analytes with varying $\mathrm{pH}$ was proposed, and the fabricated modified electrode was applied for the tap water sample analysis and good recovery results were obtained.

\section{Methods \\ Main reagents}

The allura red AC (ALR), hydroquinone and catechol were obtained from Himedia, and double-distilled water was used to prepare standard stock solutions of concentrations $25.0 \mathrm{mM}, 2.5 \times 10^{-3} \mathrm{M}$ and $2.5 \times 10^{-3} \mathrm{M}$, respectively. The $0.2 \mathrm{M}$ buffer solution of unique ionic strength and preferred $\mathrm{pH}$ was prepared from a mixture of $\mathrm{NaH}_{2} \mathrm{PO}_{4} \cdot \mathrm{H}_{2} \mathrm{O}$ and $\mathrm{Na}_{2} \mathrm{HPO}_{4}$. Before any electrochemical measurements, the working electrode was cleaned with $1 \mu \mathrm{m}, 0.3 \mu \mathrm{m}$ and $0.05 \mu \mathrm{m}$ of $\alpha$-alumina slurry on the polishing pad and ultrasonicated in an equimolar mixture of ethanol and water for $15 \mathrm{~min}$, later rinsed with double-distilled water. All the chemicals were of analytical grade and used as received without any additional treatment.

\section{Instrumentation}

AUTOLAB potentiostat with PGSTAT 302 was used for all the electrochemical experiments. The surface morphology of the working electrodes was characterized by using ultra-high-resolution field emission scanning electron microscope (FESEM, FEI, \& Nova NanoSEM450) instrument operating at $25 \mathrm{kV}$. The working electrode used for this study was glassy carbon electrode with 3.0 $\mathrm{mm}$ in diameter. A platinum wire was used as a counter electrode and $\mathrm{Ag} / \mathrm{AgCl}$, saturated $\mathrm{KCl}$, as a reference electrode. All the electrochemical experiments were carried out at an ambient temperature of $25 \pm 0.1{ }^{\circ} \mathrm{C}$; the corresponding redox potentials were recorded with respect to $\mathrm{Ag} / \mathrm{AgCl}$ electrode. 


\section{Results and discussion}

Fabrication of ALR/GCE and its electrochemical characterization

In order to boost the performance of the bare GCE, electropolymerization of allura red was carried out on the glassy carbon working electrode by preparing $1.0 \mathrm{mM}$ aqueous solution of ALR monomer along with $0.1 \mathrm{M}$ $\mathrm{NaOH}$ solution as a supporting electrolyte. The potential window was maintained from -0.8 to $1.2 \mathrm{~V}$ with a fixed scan rate of $0.1 \mathrm{Vs}^{-1}$ for ten consecutive cycles as shown in Figure S1. During the progression of electropolymerization, the voltammogram has gradually descended with increased number of cycles, indicating the growth of the ALR polymer chain on the surface of GCE. After few consecutive cycles, the voltammogram tends to be constant with stable current signal reflecting the achievement of saturation level in the electropolymerization phenomenon (He et al. 2014). As the number of cyclic sweeps increases, a decreased electrocatalytic property was observed at the fabricated electrode due to the thickness of polymeric film (Ganesh et al. 2015; Wang et al. 2007a, 2007b, 2007c; Wang et al. 2006). Therefore, it was concluded that ten sweep cycles of CV are best suitable to get a strong electrocatalytic response.

Figure S2A represents the CVs for the $\left[\mathrm{Fe}(\mathrm{CN})_{6}\right]^{4-/ 3-}$ in the electrochemical cell with $1 \mathrm{M} \mathrm{KCl}$ as the supporting electrolyte at bare GCE and ALR/GCE electrodes with $0.05 \mathrm{Vs}^{-1}$ scan rate. From the graph, it was observed that the $\mathrm{CV}$ response obtained at fabricated ALR/GCE was with sharp and static enhancement, and peak potential separation was observed to be $0.064 \mathrm{~V}$, which was a characteristic voltammogram of $\left[\mathrm{Fe}(\mathrm{CN})_{6}\right]^{4-/ 3-}$ redox couple (Kumar et al. 2017). The Randles-Sevcik equation was used to calculate the active surface area of the working electrodes (Ganesh et al. 2015; Kumar et al. 2019), which was found to be $0.0289 \mathrm{~cm}^{2}$ and $0.0319 \mathrm{~cm}^{2}$ for bare GCE and ALR/GCE, respectively. The approximate surface coverage of ALR deposit on GCE was calculated by Eq. 1 (Wang, 1994; Ganesh et al. 2018).

$$
\mathrm{Ip}=\mathrm{n}^{2} \mathrm{~F}^{2} \mathrm{A \Gamma v} / 4 \mathrm{RT}
$$

Here, $\Gamma, A$, Ip, $n$ and $v$ represents the surface coverage concentration, surface area of the working electrode, peak current, number of electrons involved and scan rate, respectively. $\mathrm{F}, \mathrm{R}$ and $\mathrm{T}$ have their usual significance. The $\Gamma$ was calculated to be $0.1006 \times 10^{-10} \mathrm{M} / \mathrm{cm}^{2}$ for ALR/GCE electrode. Figure S2B showed the surface morphology of the bare GCE (a) and ALR/GCE (b), which showed that the surface imperfections were covered by a thin layer of ALR, which proficiently diminished the trapping of analytes at ALR/GCE surface (Mansour et al. 2019).

\section{Electrocatalytic response of $\mathrm{CC}$ and $\mathrm{HQ}$ in a binary mixture at ALR/GCE}

The electrocatalytic oxidation of $\mathrm{CC}$ and HQ was carried out by using $\mathrm{CV}$ technique. Figures 1 and 2 represent the CVs obtained for the oxidation of $40.0 \mu \mathrm{M} \mathrm{CC}$ and 40.0 $\mu \mathrm{M}$ HQ in $0.2 \mathrm{M}$ buffer of $\mathrm{pH} 7.4$ at bare GCE (curve a) and ALR/GCE (curve b), respectively, with a scan rate of $0.05 \mathrm{Vs}^{-1}$. It can be observed from both figures that the voltammetric response of CC and HQ at bare GCE (curve a) was wide, with poor in sensitivity, and the oxidation signals were located at $0.225 \mathrm{~V}$ and $0.182 \mathrm{~V}$, respectively. However, the ALR/GCE (curve b) favoured the oxidation

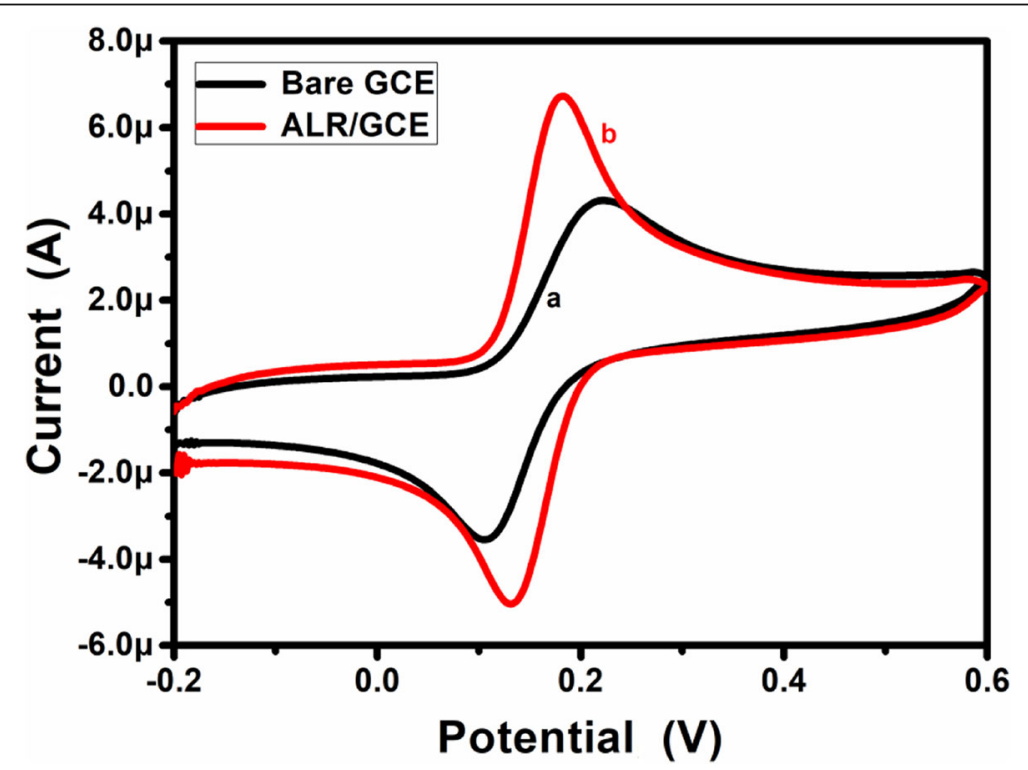

Fig. 1 CVs of $40.0 \mu \mathrm{M}$ CC at bare GCE (curve a) and ALR/GCE (curve b) in $0.2 \mathrm{M}$ buffer of pH 7.4 with $0.05 \mathrm{Vs}^{-1}$ scan rate 


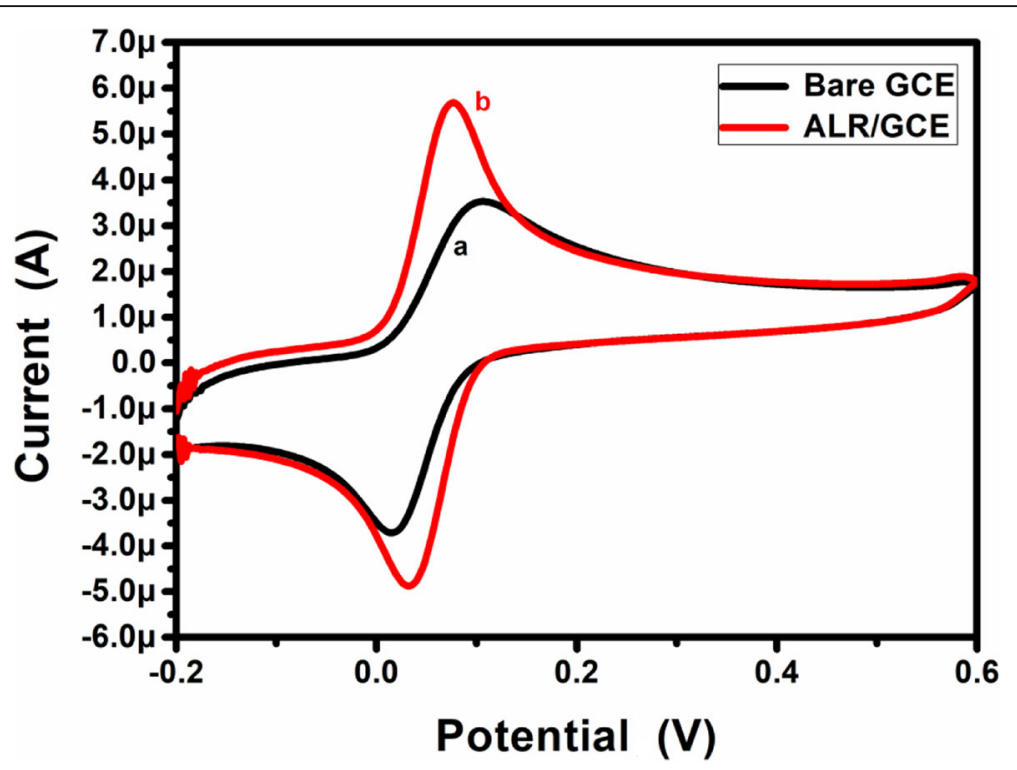

Fig. $2 \mathrm{CVs}$ of $40.0 \mu \mathrm{M} \mathrm{HQ}$ at bare GCE (curve a) and ALR/GCE (curve b) in $0.2 \mathrm{M}$ buffer of $\mathrm{pH} 7.4$ with $0.05 \mathrm{Vs}^{-1}$ scan rate

process of both analytes, and the signals were observed at $0.181 \mathrm{~V}$ and $0.108 \mathrm{~V}$, respectively, for $\mathrm{CC}$ and $\mathrm{HQ}$. The refinement of shift in the oxidation signal was due to the electrocatalytic capability of the ALR/GCE towards the electrooxidation of dihydroxy benzene isomers.

The chief task of the ALR/GCE is to resolve the overlapped oxidation signals of $\mathrm{CC}$ and $\mathrm{HQ}$ isomers, which is practically impossible at bare GCE. Due to the similarity in chemical structure and fouling of the electrode surface, bare GCE fails in the judgment of oxidation signals of these isomers. Figure 3 evidently shows the cyclic voltammograms for equimolar binary mixture $(40.0 \mu \mathrm{M})$ of $\mathrm{CC}$ and $\mathrm{HQ}$ with $0.2 \mathrm{M}$ buffer of $\mathrm{pH} 7.4$ at $0.05 \mathrm{Vs}^{-1}$ scan rate. At bare GCE, overlain wide voltammogram was observed at an oxidation potential of $0.208 \mathrm{~V}$ which is of no technical significance. However, at ALR/GCE, a strong separation was obtained for $\mathrm{CC}$ and $\mathrm{HQ}$ at potentials which were as similar to their individual determination. The difference in oxidation peak separation was calculated to be $0.102 \mathrm{~V}$, which was more adequate for the interference-free determination of these isomers in a dual mixture. At fabricated ALR/GCE, the oxidation of

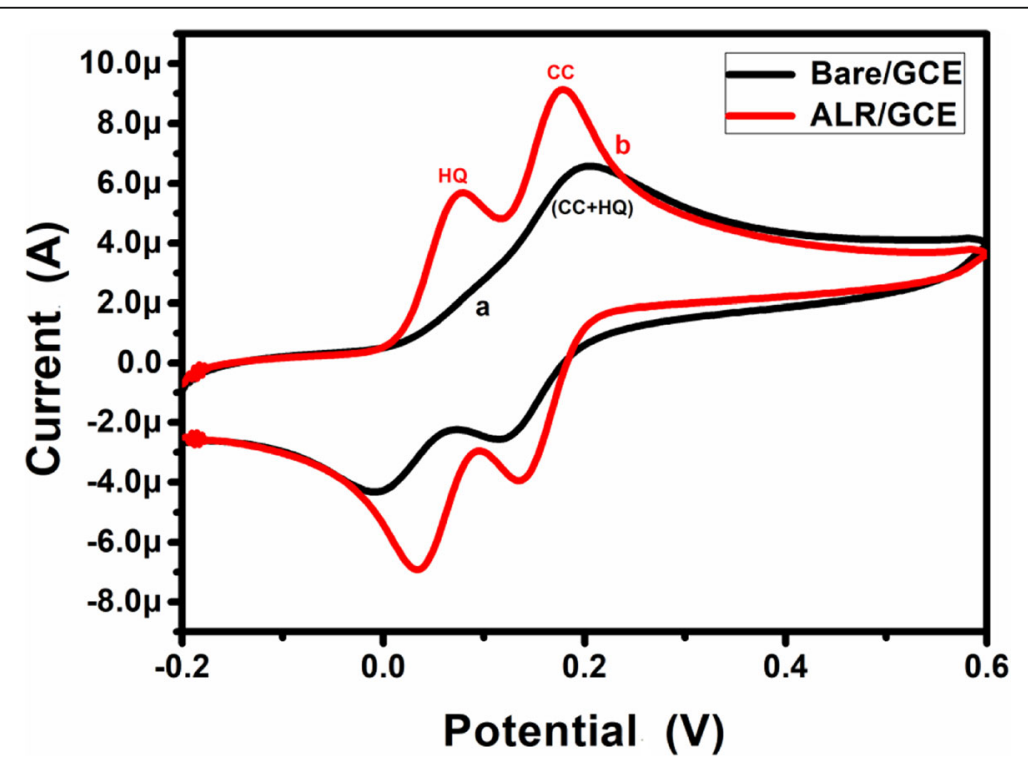

Fig. $3 \mathrm{CV}$ s recorded for the simultaneous determination of equimolar ( $40.0 \mu \mathrm{M}$ ) binary mixture of CC and HQ at bare GCE (curve a) and ALR/GCE (curve b) with $0.2 \mathrm{M}$ buffer of $\mathrm{pH} 7.4$ with $0.05 \mathrm{Vs}^{-1}$ scan rate 


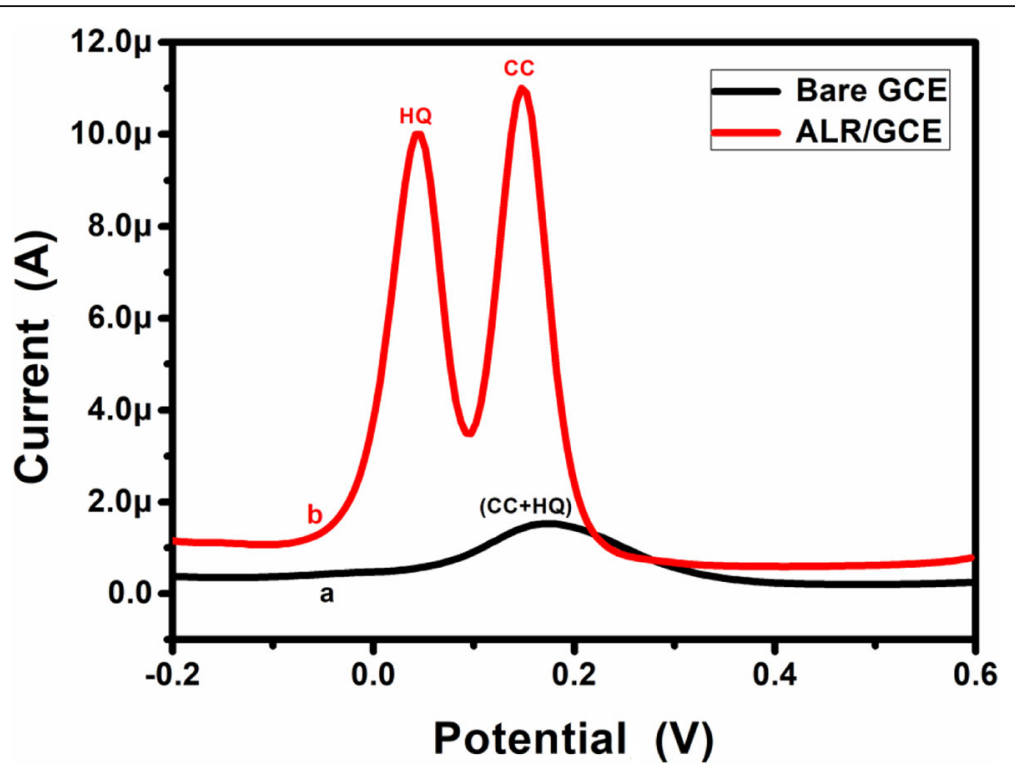

Fig. $4 \mathrm{DPV}$ s recorded for the simultaneous determination of equimolar ( $40.0 \mu \mathrm{M})$ binary mixture of $\mathrm{CC}$ and $\mathrm{HQ}$ at bare GCE (Curve a) and ALR/ GCE (curve b) with $0.2 \mathrm{M}$ buffer of $\mathrm{pH} 7.4$

HQ becomes easier than CC; furthermore, the oxidation potential of $\mathrm{HQ}$ shifts to negative side and oxidized well before reaching the oxidation potential of $\mathrm{CC}$ which leads a successful separation of these targeted analytes (Wang et al. 2007a, 2007b, 2007c). The results obtained at $\mathrm{CV}$ are again confirmed by ultra-sensitive differential pulse voltammetry (DPV) method due to the absence of background current as shown in Fig. 4. The distinguishable signals were not obtained at bare GCE (curve a), and a broad overlapped signal was observed at $0.179 \mathrm{~V}$. However, the ALR/GCE (curve b) showed selectively resolved oxidation peaks at $0.147 \mathrm{~V}$ and $0.044 \mathrm{~V}$ for CC

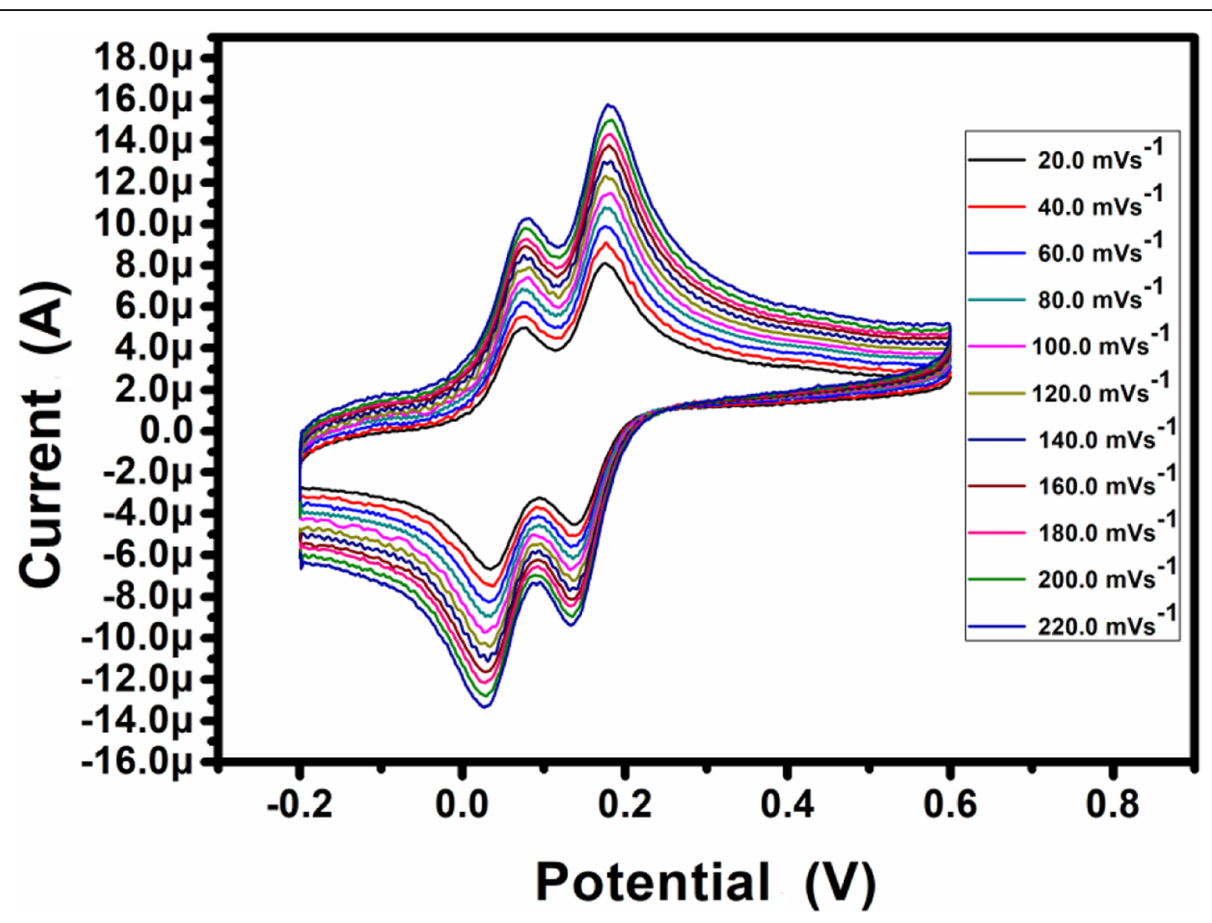

Fig. 5 CVs on impact of scan rates on electrooxidation of equimolar $(40.0 \mu \mathrm{M})$ binary mixture of CC and HQ at ALR/GCE with $0.2 \mathrm{M}$ buffer of $\mathrm{pH} 7.4$ 
Table $1 k^{0}$ values calculated for the electrooxidation of CC and $\mathrm{HQ}$

\begin{tabular}{|c|c|c|c|c|}
\hline \multirow{2}{*}{$\begin{array}{l}u \\
\left(V s^{-1}\right)\end{array}$} & \multicolumn{2}{|l|}{$\Delta \mathrm{Ep}(\mathrm{V})$} & \multicolumn{2}{|l|}{$k^{0}\left(\mathrm{~s}^{-1}\right)$} \\
\hline & Catechol & Hydroquinone & Catechol & Hydroquinone \\
\hline 0.02 & 0.0362 & 0.0378 & 0.4195 & 0.4121 \\
\hline 0.04 & 0.0372 & 0.0377 & 0.8294 & 0.8248 \\
\hline 0.06 & 0.0407 & 0.0412 & 1.1956 & 1.1887 \\
\hline 0.08 & 0.0407 & 0.0413 & 1.5940 & 1.5830 \\
\hline 0.10 & 0.0407 & 0.0413 & 1.9929 & 1.9792 \\
\hline 0.12 & 0.0407 & 0.0413 & 2.3911 & 2.3746 \\
\hline 0.14 & 0.0407 & 0.0413 & 2.7899 & 2.7707 \\
\hline 0.16 & 0.0440 & 0.0483 & 3.0704 & 2.9228 \\
\hline 0.18 & 0.0442 & 0.0483 & 3.4442 & 3.2877 \\
\hline 0.20 & 0.0478 & 0.0483 & 3.6745 & 3.6534 \\
\hline 0.22 & 0.0478 & 0.0483 & 4.0421 & 4.0188 \\
\hline
\end{tabular}

and $\mathrm{HQ}$, respectively. The peak potential separation was determined to be $0.103 \mathrm{~V}$. This peak potential difference was more sufficient for simultaneous determination of dihydroxy benzene isomers.

\section{Impact of scan rate and $\mathrm{pH}$}

The impact of varying scan rates on the determination of equimolar $(40.0 \mu \mathrm{M})$ mixture of $\mathrm{CC}$ and $\mathrm{HQ}$ in $0.2 \mathrm{M}$ buffer of pH 7.4 was examined. It can be seen from Fig. 5 that there was an increase in peak current with the increase in scan rate, and a slight shift in the redox potentials were observed, which was in accordance with the RandlesSevcik equation (Kumar et al. 2019). It can be observed from Figure S3A and S3B that a good linearity was observed for the plots of anodic peak current (Ipa) versus scan rate $(v)$ with correlation coefficient $\left(r^{2}\right)$ of 0.9945 and 0.9949 , respectively, for CC and HQ. On the other hand, the relationship between the Ipa and the square root of scan rate $\left(v^{1 / 2}\right)$ of CC and HQ gives a $r^{2}$ value of 0.9909 and 0.9902, respectively, as shown in Figure S3C and S3D. According to the previous reported literature, the linear establishment of Ipa versus $v$ suggests an electrode phenomenon dominated by the adsorption-controlled process at ALR/GCE (Ganesh et al. 2015; Kumar et al. 2019). To calculate the values of rate constant $\left(k^{0}\right)$, Eq. 2 was used (Bard \& Faulkner, 2001; Avendano et al. 2007). And the obtained values of $k^{0}$ for electrooxidation of CC and HQ were tabulated in Table 1.

$$
\Delta \mathrm{Ep}=201.39 \log \left(\mathrm{v} / \mathrm{k}^{0}\right)-301.78
$$

The electrochemical experiments performed in aqueous solutions directly depend on the $\mathrm{pH}$ of the supporting electrolyte. Figure 6a showed the effect of variation of buffer $\mathrm{pH}$ on the oxidation of equimolar $(40.0 \mu \mathrm{M})$ binary

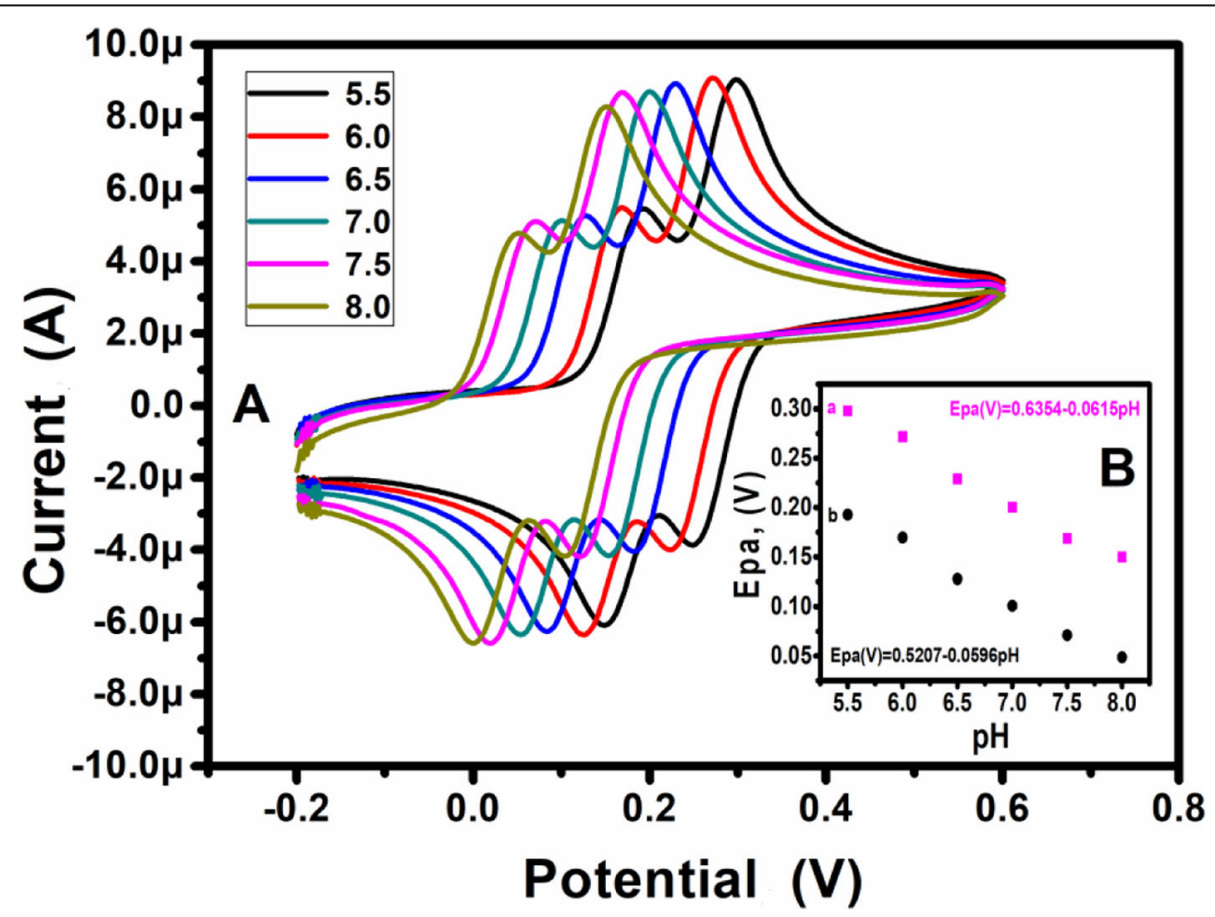

Fig. 6 a CVs obtained for $40.0 \mu \mathrm{M} \mathrm{CC}$ and $\mathrm{HQ}$ binary mixture at ALR/GCE of different $\mathrm{pH}$ (5.5 to 8.0) at $0.05 \mathrm{Vs}^{-1}$ scan rate. $\mathbf{b}$ Influence of pH on anodic peak potential of analytes 


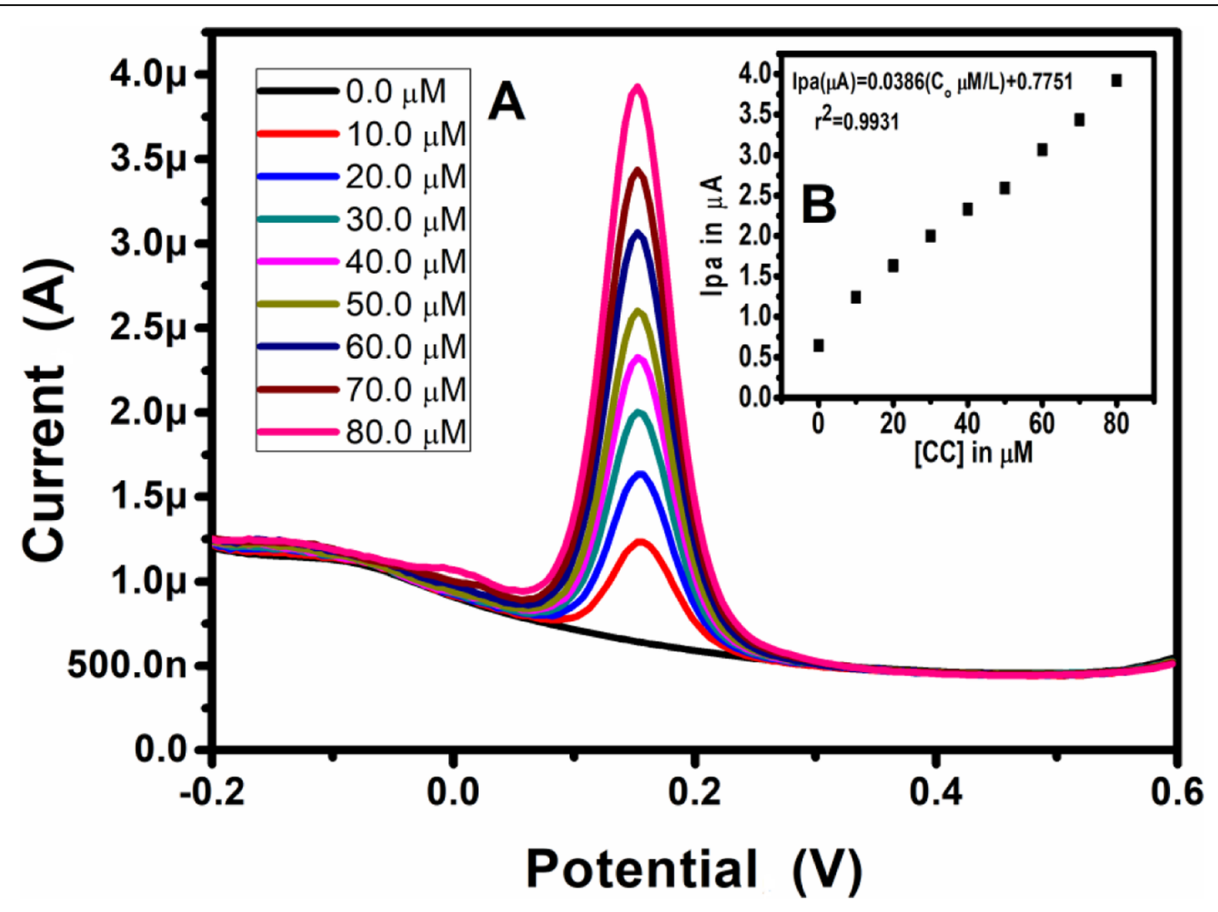

Fig. 7 a DPVs of ALR/GCE with different concentrations of CC (0 to $80.0 \mu \mathrm{M})$. b Linear plot of Ipa versus concentration of CC

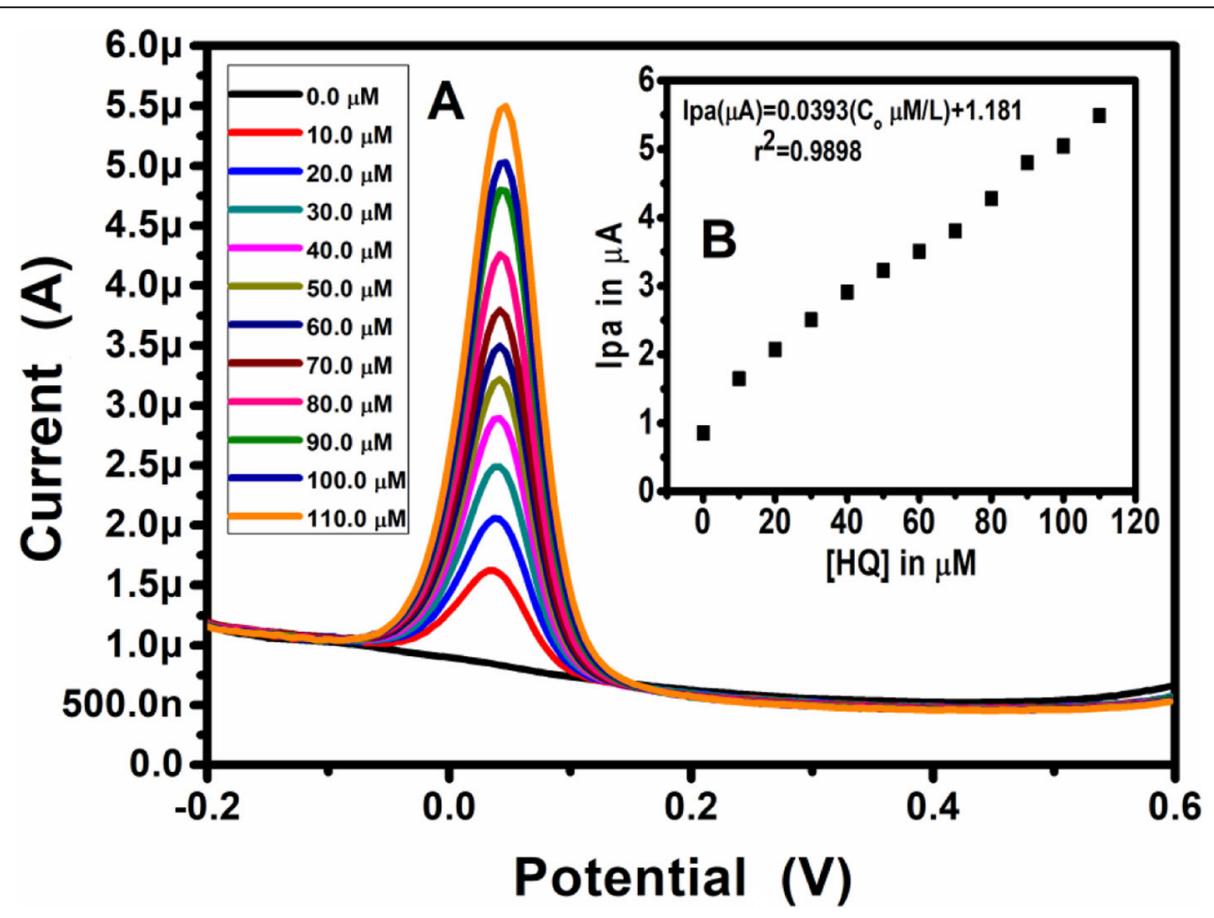

Fig. 8 a DPVs of ALR/GCE with different concentrations of HQ (0 to $110.0 \mu \mathrm{M})$. $\mathbf{b}$ Linear plot of Ipa versus concentration of $\mathrm{HQ}$ 
Table 2 Comparison of LOD obtained for CC and HQ at ALR/GCE with other modified electrodes, method and pH of the supporting electrolyte used

\begin{tabular}{|c|c|c|c|c|c|c|c|}
\hline \multirow[t]{2}{*}{ Working electrode } & \multicolumn{2}{|c|}{$\begin{array}{l}\text { Limit of } \\
\text { detection }(\mu \mathrm{M})\end{array}$} & \multicolumn{2}{|c|}{ Linear range $(\mu \mathrm{M})$} & \multirow{2}{*}{$\begin{array}{l}\mathrm{pH} \text { of } \\
\text { supporting } \\
\text { electrolyte }\end{array}$} & \multirow[t]{2}{*}{ Method } & \multirow[t]{2}{*}{ References } \\
\hline & $\overline{C C}$ & $\mathrm{HQ}$ & $\overline{\mathrm{CC}}$ & $\mathrm{HQ}$ & & & \\
\hline Poly(niacinamide)/GCE & 0.31 & 0.24 & 10 to 120 & 10 to 160 & 7.4 & CV & Kumar et al. 2017 \\
\hline Eosin $Y / G C E$ & 0.12 & 0.14 & 1.0 to 130 & 1.0 to 130 & 5.0 & DPV & He et al. 2014 \\
\hline c-MWCNTs/CTS/Au /GCE & 0.89 & 0.17 & 5 to 900 & 0.5 to 1500 & 7.0 & DPV & Shen et al. 2017 \\
\hline PDA-RGO/GCE & 0.74 & 0.62 & 1.0 to 230 & 1.0 to 250 & 6.5 & DPV & Zheng et al. 2013 \\
\hline Poly(phenylalanine) & 0.70 & 1.0 & 10.0 to 140.0 & 10.0 to 140.0 & 5.0 & DPV & Wang et al. 2006 \\
\hline $\mathrm{BG} / \mathrm{GCE}$ & 0.20 & 0.30 & 1.0 to 75.0 & 5.0 to 100 & 5.6 & DPV & Zhang et al. 2015 \\
\hline Poly(3-thiophenemalonic acid) GCE & 3.91 & 7.81 & 3.91 to 500 & 7.81 to 500 & 6.8 & DPV & Xu et al. 2015 \\
\hline LRG/GCE & 0.80 & 0.50 & 3.0 to 300 & 1.0 to 300 & 6.5 & DPV & Lai et al. 2014 \\
\hline Eosin $Y / C P E$ & 0.27 & 0.79 & 51 to 357 & 51 to 357 & 7.4 & CV & Ganesh \& Swamy, 2016 \\
\hline Poly(methionine) MCPE & 45.8 & 55.66 & 20.66 to 209.92 & 20.66 to 192.30 & 7.4 & CV & Ganesh et al. 2017 \\
\hline Silsesquioxane/MCPE & 10.0 & 10.0 & 10.0 to 300.0 & 10.0 to 450.0 & 7.0 & DPV & Da-Silva et al. 2013 \\
\hline MWNT/GCE & 0.2 & 0.75 & 0.6 to 100.0 & 1.0 to 100.0 & 4.5 & DPV & Qi et al. 2005 \\
\hline (LDHf/GCE) & 1.2 & 9.0 & 3.0 to 1500.0 & 12.0 to 800.0 & 6.5 & DPV & Li et al. 2009 \\
\hline Poly-p-ABA/GCE & 0.5 & 0.4 & 2.0 to 900.0 & 1.2 to 600.0 & 7.0 & DPV & Yang et al. 2009 \\
\hline MWCNT-modified electrode & 0.6 & 0.6 & 2.0 to 100.0 & 2.0 to 100.0 & 5.5 & LSV & Ding et al. 2005 \\
\hline PASA/MWNTs/GCE & 1.0 & 1.0 & 6.0 to 180.0 & 6.0 to 100.0 & 6.0 & DPV & Zhao et al. 2009 \\
\hline Micellar effect/GCE & 0.5 & 0.5 & 0.5 to 900.0 & 0.5 to 1400.0 & 6.8 & DPV & Peng et al. 2006 \\
\hline Pen-modified electrode & 0.6 & 1.0 & 25.0 to 175.0 & 15.0 to 115.0 & 5.0 & DPV & Wang et al. 2007c \\
\hline $\mathrm{Pt} / \mathrm{ZrO} 2-\mathrm{RGO} / \mathrm{GCE}$ & 0.4 & 0.4 & 1.0 to 400.0 & 1.0 to 1000.0 & 7.0 & DPV & Vilian et al. 2014 \\
\hline TRGO/GCE & 0.8 & 0.75 & 1.0 to 500.0 & 1.0 to 500.0 & 6.0 & DPV & Li et al. 2012 \\
\hline PEDOT/GO modified electrode & 1.6 & 1.6 & 2.0 to 400.0 & 2.5 to 200.0 & 6.0 & DPV & Si et al. 2012 \\
\hline Graphene-chitosan/GCE & 0.75 & 0.75 & 1.0 to 400.0 & 1.0 to 300.0 & 7.0 & DPV & Yin et al. 2011 \\
\hline$\left[\mathrm{Cu}(\mathrm{Sal}-\beta-\mathrm{Ala})(3,5-\mathrm{DMPz})_{2}\right] / \mathrm{MWCNTs} / \mathrm{GCE}$ & 3.5 & 1.46 & 5.0 to 215.0 & 5.0 to 370.0 & 6.0 & DPV & Alshahrani et al. 2014 \\
\hline $\mathrm{CNx} / \mathrm{GCE}$ & 2.71 & 1.20 & 0.2 to 1000.0 & 0.1 to 1000.0 & 4.7 & LSV & Dong et al. 2008 \\
\hline MWCNT-NF-PMG/GCE & 31.0 & 18.1 & 49.8 to 3650.8 & 49.8 to 3921.0 & 1.5 & CV & Umasankar et al. 2011 \\
\hline RGO-MWNTs & 1.8 & 2.6 & 5.5 to 540.0 & 8.0 to 391.0 & 7.0 & DPV & Hu et al. 2012 \\
\hline $\mathrm{IL} / \mathrm{CPE}$ & --- & 4.0 & --- & 10.0 to 1500.0 & 7.0 & DPV & Zhang \& Zheng, 2007 \\
\hline Poly(benzydamine)/CPE & 5.79 & 3.78 & 10.0 to 60.0 & 10.0 to 60.0 & 7.4 & CV & Sukanya et al. 2020 \\
\hline Poly(benzoguanamine)/CPE & 2.55 & 3.84 & 10.0 to 90.0 & 10.0 to 90.0 & 7.4 & $C V$ & Chetankumar et al. 2019 \\
\hline Poly(glycine)/CPE & 0.16 & 0.20 & 20.0 to 180.0 & 20.0 to 180.0 & 7.4 & CV & Harisha et al. 2018 \\
\hline Poly(direct yellow 11)/MPG & 0.11 & 0.16 & 10.0 to 60.0 & 10.0 to 70.0 & 7.4 & CV & Chetankumar et al. 2020 \\
\hline Poly(OPD)/MCPE & 1.1 & 2.1 & 10.0 to 90.0 & 10.0 to 90.0 & 7.4 & CV & Chetankumar \& Swamy, 2019 \\
\hline ALR/GCE & 0.126 & 0.132 & 0 to 80.0 & 0 to 110.0 & 7.4 & DPV & This work \\
\hline
\end{tabular}

mixture of $\mathrm{CC}$ and $\mathrm{HQ}$ by $\mathrm{CV}$ technique. As the $\mathrm{pH}$ of the supporting electrolyte increases, the redox potential shifts towards the least potential. A linear graph was observed between oxidation peak potential (Epa) and $\mathrm{pH}$ of the buffer solution, and the slope of the linearity was found to be 0.0615 and 0.0596 for CC and HQ respectively, as in inset Fig. 6b. The linear regression equation can be expressed as Epa $(\mathrm{V})=0.6354$ $-0.0615(\mathrm{pH}), r^{2}=0.9950$ for CC, and Epa $(\mathrm{V})=$ 0.5207-0.0596 (pH), $r^{2}=0.9912$ for HQ. Moreover, the obtained slope values in both linearities were in strong agreement with Nernst equation for identical number of protons and electrons transfer (Ganesh \& Swamy, 2015; Kumar et al. 2019). 


\section{Concentration study}

The concentration studies of both the targeted analytes were carried out at ALR/GCE by ultra-sensitive DPV technique. Figures $7 \mathrm{a}$ and $8 \mathrm{a}$ showed an increment in the current signal due to the increase in concentration of CC and HQ. The linearity graphs of Ipa versus concentration of $\mathrm{CC}$ and $\mathrm{HQ}$ were shown in insets Fig. 7b and $8 \mathrm{~b}$, respectively. The linear regression equations obtained are as follows:

$$
\begin{aligned}
\operatorname{Ipa}(\mu \mathrm{A})= & 0.0386\left(\mathrm{C}_{0} \mu \mathrm{M} / \mathrm{L}\right) \\
& +0.7751,\left(\mathrm{r}^{2}=0.9931\right)
\end{aligned}
$$

and

$$
\begin{aligned}
\text { Ipa }(\mu \mathrm{A})= & 0.0393\left(\mathrm{C}_{0} \mu \mathrm{M} / \mathrm{L}\right) \\
& +1.1810,\left(\mathrm{r}^{2}=0.9898\right)
\end{aligned}
$$

for $\mathrm{CC}$ and $\mathrm{HQ}$, respectively.

The limit of detection (LOD) and limit of quantification (LOQ) were calculated by using Eqs. 3 and 4, where $S$ is the standard deviation of the six blank measurements and $M$ is the slope of the calibration graph (Wang et al. 1994; Ganesh et al. 2018).

$$
\begin{aligned}
& \mathrm{LOD}=3 \mathrm{~S} / \mathrm{M} \\
& \mathrm{LOQ}=10 \mathrm{~S} / \mathrm{M}
\end{aligned}
$$

The LOD values of CC and HQ were calculated to be $0.126 \mu \mathrm{M}$ and $0.132 \mu \mathrm{M}$, respectively, which are relatively lower than our own previous reports and available recent literature reports as tabulated in Table 2 (Kumar et al. 2017; He et al. 2014; Shen et al. 2017; Zheng et al. 2013; Wang et al. 2006; Zhang et al. 2015; Xu et al. 2015; Lai et al. 2014; Ganesh \& Swamy, 2016; Ganesh et al. 2017; Da-Silva et al. 2013; Qi \& Zhang, 2005; Li et al. 2009; Yang et al. 2009; Ding et al. 2005; Zhao et al. 2009; Peng \& Gao, 2006; Wang et al. 2007a, 2007b, 2007c, Vilian et al. 2014; Li et al. 2012; Si et al. 2012; Yin et al. 2011; Alshahrani et al. 2014; Dong et al. 2008; Umasankar et al. 2011; Hu et al. 2012; Zhang \& Zheng, 2007; Sukanya et al. 2020; Chetankumar et al. 2019; Harisha et al. 2018; Chetankumar et al. 2020; Chetankumar \& Swamy, 2019).

Because of the similar oxidation potential, an individual determination of either $\mathrm{CC}$ or HQ in a binary mixture is a task with high difficulty and these isomers interfere each other in their simultaneous determination. The interference study was performed by keeping the concentration of one analyte constant and varying the concentration of the other one by ultra-sensitive DPV technique. We recorded the DPV in the absence of analyte (blank reading) to show there is no appearance of oxidative current signal at ALR/GCE at zero concentration of the analyte. Figure 9a shows that as the concentration of CC was varied in a linear range of 0.0 to 100.0 $\mu \mathrm{M}$ by keeping the HQ concentration constant (20.0 $\mu \mathrm{M})$, we can observe an increase in peak current due to

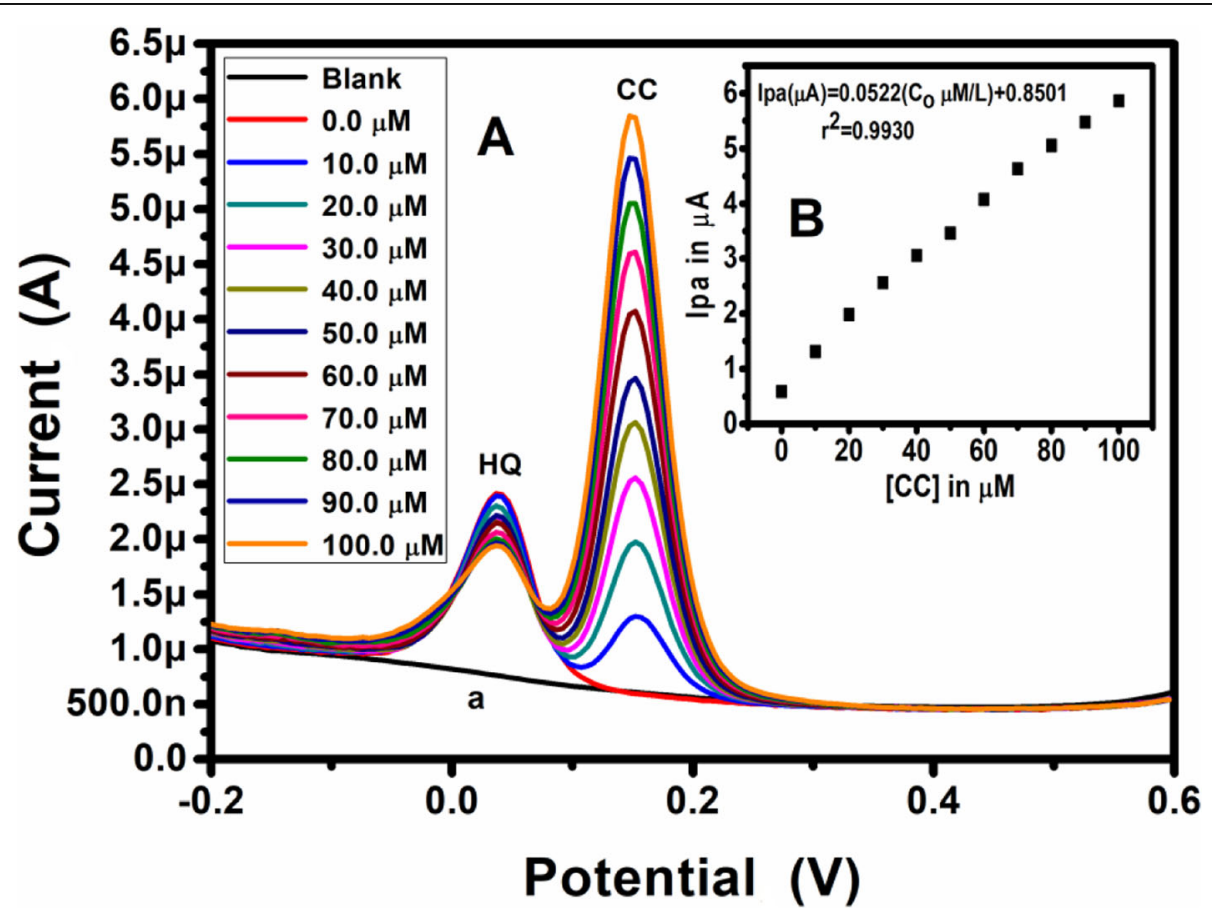

Fig. 9 a DPVs of varying concentrations of CC in presence of $20.0 \mu \mathrm{M} \mathrm{HQ}$ at ALR/GCE. b Linear plot of Ipa versus concentration of CC 


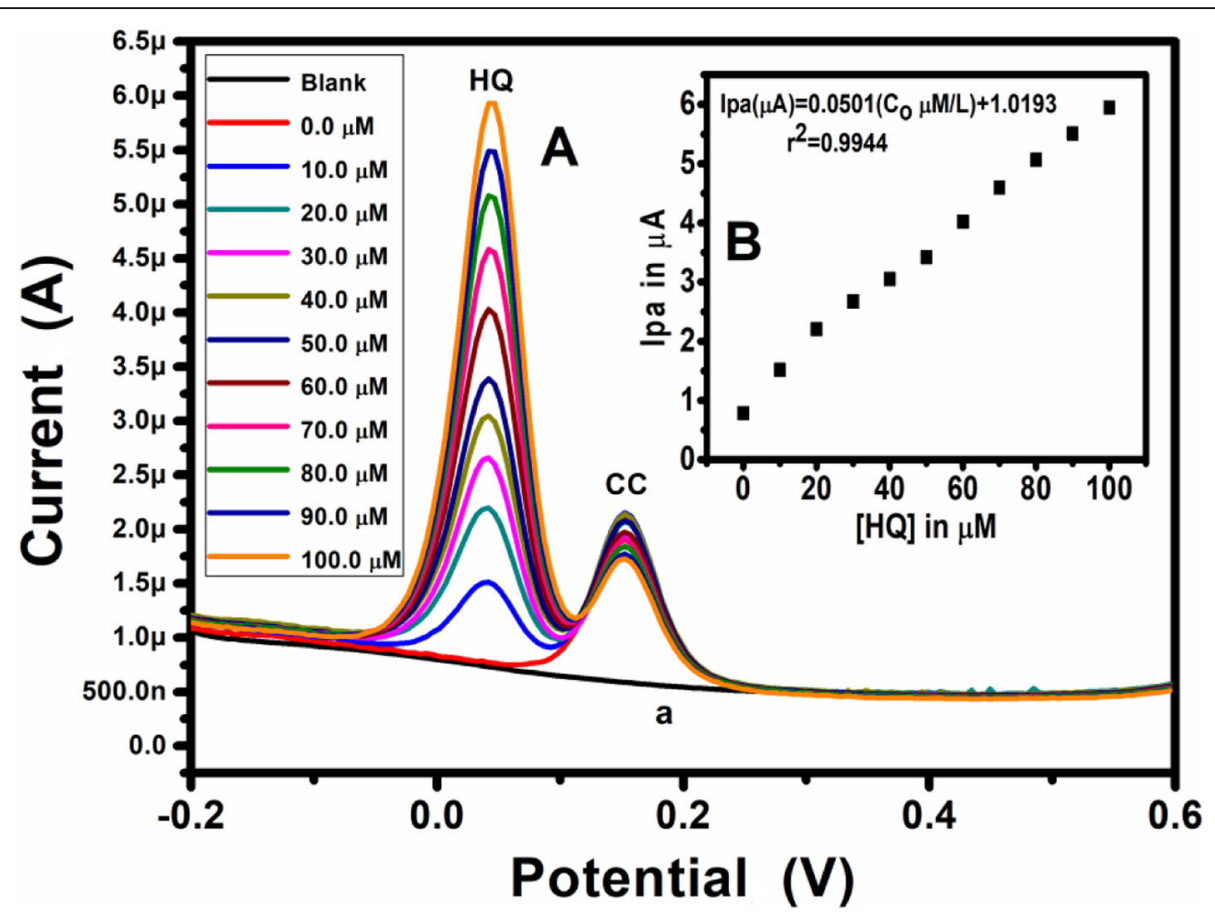

Fig. 10 a DPVs of varying concentrations of HQ in presence of $20.0 \mu \mathrm{M} C \mathrm{C}$ at ALR/GCE. b Linear plot of Ipa versus concentration of HQ

an increase in the concentration of CC only. In case of HQ too, the concentration was increased in a linear range of 0.0 to $100.0 \mu \mathrm{M}$ and that of CC was kept constant $(20.0 \mu \mathrm{M})$ as shown in Fig. 10a. From both Figs. 9a and $10 \mathrm{a}$, it can be clearly observed that the increase in the current signal was due to the increase in concentration of any one of the analytes and the other one showed constant signal which indicated that interference-free simultaneous detection is possible at ALR/GCE electrode. Moreover, in both insets Fig. $9 \mathrm{~b}$ and 10b, the peak current relationship with increasing concentration was linear. Therefore, the results reflect a successful interference-free and simultaneous determination of dihydroxy benzene isomers at ALR/GCE.

\section{Sample analysis}

As in the previous literature (Zhang et al. 2019; AlshikEdris et al. 2019), to assess the performance of the proposed method for anti-interference determination of the dihydroxy benzene isomers, the CC and HQ determination in tap water was tested and the obtained results were tabulated in Tables 3 and 4, respectively. When a known amount of $\mathrm{CC}$ was added to the tap water sample containing HQ $(10.0 \mu \mathrm{M})$, a recovery of 98.0 to $101.0 \%$ was obtained. Similarly, when a known quantity of HQ was added to the tap water sample containing CC $(10.0$ $\mu \mathrm{M})$, a good recovery of 99.2 to $102.0 \%$ was obtained. Therefore, these results are evident for the analytical applicability of the proposed ALR/GCE.

\section{Conclusion}

In the present study, we demonstrated a simple and convenient way of modifying the glassy carbon electrode by electropolymerization of allura red by cyclic voltammetric method. The fabricated working electrode showed minimization of over potential and excellent electrocatalytic activity towards the discrimination of dihydroxy benzene isomers' oxidative signals, which is practically impossible in bare working electrode. The impact of scan rate and $\mathrm{pH}$ study reveals the adsorptioncontrolled kinetics with equal number of protons and electrons transfer. The anti-interference study reflects

Table 3 Anti-interference results obtained for CC in tap water sample containing HQ at ALR/GCE $(n=5)$

\begin{tabular}{lllll}
\hline Sample number & Tap water containing $\mathrm{HQ}(\boldsymbol{\mu M})$ & $\mathrm{CC}$ added $(\boldsymbol{\mu M})$ & CC found $(\boldsymbol{\mu M})$ & Recovery $(\%)$ \\
\hline 1 & 10 & 15 & 14.7 & 98.0 \\
2 & 10 & 20 & 20.2 & 101.0 \\
3 & 10 & 25 & 24.9 & 99.6 \\
4 & 10 & 30 & 30.2 & 100.67 \\
\hline
\end{tabular}


Table 4 Anti-interference results obtained for $\mathrm{HQ}$ in tap water sample containing CC at ALR/GCE $(n=5)$

\begin{tabular}{lllll}
\hline Sample number & Tap water containing CC $(\mu \mathrm{M})$ & HQ added $(\mu \mathrm{M})$ & HQ found $(\boldsymbol{\mu M})$ & Recovery $(\%)$ \\
\hline 1 & 10 & 15 & 15.1 & 100.67 \\
2 & 10 & 20 & 20.4 & 102.0 \\
3 & 10 & 25 & 24.8 & 99.2 \\
4 & 10 & 30 & 30.4 & 101.33 \\
\hline
\end{tabular}

that the current signal of catechol and hydroquinone were independent and depend on their individual concentration in a binary mixture. The analytical application of the proposed electrochemical sensor was investigated by employing it to the water sample analysis by adding a known quantity of one analyte by keeping the other one constant, which yielded a satisfactory recovery results. Overall, a sensitive, selective, cost-effective, analytically applicable and reproducible electrochemical sensor was fabricated for the electroanalysis of dihydroxy benzene isomers.

\section{Abbreviations}

CC: CatecholHQHydroquinoneGCEBare glassy carbon electrodeALRAllura red ACALR/GCEAllura red AC glassy carbon electrodeCVCyclic voltammetryDPVDifferential pulse voltammetryLODLimit of detectionLOQLimit of quantificationFESEMField emission scanning electron microscopelpaAnodic peak currentuScan rater ${ }^{2}$ Correlation coefficient $u^{1 / 2}$ Square root of scan rate

\section{Supplementary information}

The online version contains supplementary material available at https://doi. org/10.1186/s40543-021-00270-w.

Additional file 1: Scheme S1. Chemical structure of allura red. Figure S1. CVs observed during the electropolymerization of ALR on GCE. 1.0 $\mathrm{mM}$ solution of ALR with $0.1 \mathrm{M} \mathrm{NaOH}$ at 10 cycles with $0.1 \mathrm{Vs}^{-1}$ scan rate. Figure S2. (A) CVs for bare GCE (curve a) and ALR/GCE (curve b) in $1 \mathrm{mM}$ of $\left[\mathrm{Fe}(\mathrm{CN})_{6}\right]^{4 / 3-}$ with $1 \mathrm{M} \mathrm{KCl}$ and $0.05 \mathrm{Vs}^{-1}$ scan rate. (B) SEM images for bare GCE (a) and ALR/GCE (b). Figure. S3 (A) Ipa versus $u$ of CC (B) Ipa versus $u$ of $\mathrm{HQ}(C)$ Ipa versus $u^{1 / 2}$ of $C C$ and (D) Ipa versus $u^{1 / 2}$ of $\mathrm{HQ}$.

\section{Acknowledgements}

We acknowledge the Cooperative Equipment Center at KoreaTech for the formal discussions. All the authors acknowledge the reviewers for their useful suggestions to improve the quality of the present work.

\section{Authors' contributions}

PSG, GS and SHL did the conceptualization. PSG, GS and SHL did the formal analysis. PSG, GS, SHL and SYK did the methodology. SYK and EEE did the supervision. PSG, GS and SHL are responsible for writing the original draft. PSG, GS, SHL, SYK and EEE took part in the writing - review and editing. The authors have read and approved the final version of the manuscript.

\section{Funding}

This work was supported by Education and Research Promotion Program of KOREATECH in 2021. The work was also supported by the National Research Foundation of Korea (NRF) grant funded by Ministry of Education (NRF2020R111A3065371).

Availability of data and materials Not applicable

\section{Declarations}

Competing interests

The authors declare that they have no competing interests.

Received: 18 January 2021 Accepted: 23 March 2021

Published online: 20 April 2021

\section{References}

Ahammad AJS, Rahman MM, Xu GR, Kim SH, Lee JJ. Highly sensitive and simultaneous determination of hydroquinone and catechol at poly(thionine) modified glassy carbon electrode. Electrochem Acta. 2011;56(14):5266-71. https://doi.org/10.1016/j.electacta.2011.03.004.

Ali I, Gupta VK, Khan TA, Asim M. Removal of arsenate from aqueous solution by electrocoagulation method using Al-Fe electrodes. Int J Electrochem Sci. 2013;7:1898-907.

Ali I, Jain CK. Advances in arsenic speciation techniques. Int J Environ Anal Chem. 2004;84(12):947-64. https://doi.org/10.1080/03067310410001729637.

Alshahrani LA, Li X, Luo H, Yang L, Wang M, Yan S, et al. The simultaneous electrochemical detection of catechol and hydroquinone with [Cu(Sal- $\beta$-Ala) (3,5-DMPz) 2]/SWCNTS/GCE. Sensors. 2014;14(12):22274-84. https://doi.org/1 $0.3390 / 5141222274$

Alshik-Edris NMM, Abdullah J, Kamaruzaman S, Sulaiman Y. Voltammetric determination of hydroquinone, catechol, and resorcinol by using a glassy carbon electrode modified with electrochemically reduced graphene oxidepoly(Eriochrome black T) and gold nanoparticles. Microchim Acta. 2019; 186(261):1-9. https://doi.org/10.1007/s00604-019-3376-y.

Asfaram A, Ghaedi M, Agarwal S, Tyagi I, Gupta VK. Removal of basic dye Auramine-O by ZnS:Cu nanoparticles loaded on activated carbon: optimization of parameters using response surface methodology with central composite design. RSC Adv. 2015;5:18438-50. https://doi.org/10.1039/C4RA1 5637D.

Avendano SC, Angeles GA, Ramirez-Silva MT, Rosquete-Pina G, Romero-Romo M, Palomar-Pardave M. On the electrochemistry of dopamine in aqueous solution. Part I: The role of [SDS] on the voltammetric behavior of dopamine on a carbon paste electrode. J Electroanal Chem. 2007;609(1):17-26. https:// doi.org/10.1016/j.jelechem.2007.05.021.

Bard AJ, Faulkner LR. Electrochemical methods fundamentals and applications. New York: Wiley; 2001. p. 2.

Bottari D, Pigani L, Zanardi C, Terzi F, Paturca SV, Grigorescu SD, et al. Electrochemical sensing of caffeic acid using gold nanoparticles embedded in poly(3,4-ethylenedioxythiophene) layer by Si-nusoidal voltage procedure. Chemosensors. 2019;7(4):65. https://doi.org/10.3390/chemosensors7040065.

Buleandra M, Rabinca AA, Mihailciuc C, Balan A, Nichita C, Stamatin I, et al. Screen-printed Prussian Blue modified electrode for simultaneous detection of hydroquinone and catechol. Sens Actuators B. 2014;203:824-32. https:// doi.org/10.1016/j.snb.2014.07.043.

Chandrashekar BN, Lv W, Jayaprakash GK, Harrath K, Liu LWY, Swamy BEK. Cyclic voltammetric and quantum chemical studies of a poly(methionine) modified carbon paste electrode for simultaneous detection of dopamine and uric acid. Chemosensors. 2019;7(2):24. https://doi.org/10.3390/chemosensors7020024.

Chao GKJ, Suatoni JC. Determination of phenolic compounds by HPLC. J. Chromatogr. Sci. 1982;20(9):436-40. https://doi.org/10.1093/chromsci/20.9.436.

Chetankumar K, Swamy BEK. Electrochemical investigation of catechol and hydroquinone at poly(o-phenylenediamine) modified carbon paste electrode: a voltammetric study. Anal Bioanal Electrochem. 2019;1 1(12):1638-50.

Chetankumar K, Swamy BEK, Sharma SC. Poly (benzoguanamine) modified sensor for catechol in presence of hydroquinone: a voltammetric study. J Electroanal Chem. 2019;849:113365. https://doi.org/10.1016/j.jelechem.201 9.113365. 
Chetankumar K, Swamy BEK, Sharma SC. Electrochemical preparation of poly (direct yellow 11) modified pencil graphite electrode sensor for catechol and hydroquinone in presence of resorcinol: a voltammetric study. Microchem. J. 2020;156:104979. https://doi.org/10.1016/..microc.2020.104979.

Da-Silva PS, Gasparini BC, Magosso HA, Spinelli A. Electrochemical behavior of hydroquinone and catechol at a silsesquioxane modified carbon paste electrode. J Braz Chem Soc. 2013;24(4):695-9. https://doi.org/10.5935/01035053.20130079.

Dehghani MH, Sanaei D, Ali I, Bhatnagar A. Removal of chromium(VI) from aqueous solution using treated waste newspaper as a low-cost adsorbent: kinetic modeling and isotherm studies. J Mol Liq. 2016;215:671-9. https://doi. org/10.1016/j.molliq.2015.12.057.

Ding YP, Liu WL, Wu QS, Wang XG. Direct simultaneous determination of dihydroxybenzene isomers at C-nanotube-modified electrodes by derivative voltammetry. J Electroanal Chem. 2005;575(2):275-80. https://doi.org/10.101 6/j.jelechem.2004.09.020.

Dong J, Qu X, Wang L, Zhao C, Xu J. Electrochemistry of nitrogen-doped carbon nanotubes (CNx) with different nitrogen content and its application in simultaneous determination of dihydroxybenzene isomers. Electroanal. 2008; 20(18):1981-6. https://doi.org/10.1002/elan.200804274.

El-Shishtawy RR, Rahman MM, Sheikh TA, Arshad MN, Al-Zahrani FAM, Asiri AM. A New $\mathrm{Cr}^{3+}$ Electrochemical sensor based on ATNA/Nafion/glassy carbon electrode. Materials. 2020;13(12):2695. https://doi.org/10.3390/ma13122695.

Ganesh PS, Swamy BEK. Simultaneous electroanalysis of hydroquinone and catechol at poly(brilliant blue) modified carbon paste electrode: a voltammetric study. J Electroanal Chem. 2015;756:193-200. https://doi.org/1 0.1016/j.jelechem.2015.08.027.

Ganesh PS, Swamy BEK. Voltammetric resolution of catechol and hydroquinone at eosin Y film modified carbon paste electrode. J Mol Liq. 2016;220:208-15. https://doi.org/10.1016/..molliq.2016.04.078.

Ganesh PS, Swamy BEK, Fayemi OE, Sherif EM, Ebenso EE. Poly(crystal violet) modified pencil graphite electrode sensor for the electroanalysis of catechol in the presence of hydroquinone. Sensing Bio-Sensing Res. 2018;20:47-54. https://doi.org/10.1016/j.sbsr.2018.08.001.

Ganesh PS, Swamy BEK, Harisha KV. Electropolymerisation of DL-methionine at carbon paste electrode and its application to the determination of catechol and hydroquinone. Anal Bioanal Electrochem. 2017;9(1):47-64.

Gavrilescu M, Chisti Y. Biotechnology-a sustainable alternative for chemical industry. Biotechnol Adv. 2005;23(7-8):471-99. https://doi.org/10.1016/j. biotechadv.2005.03.004.

Ghaedi M, Hajjati S, Mahmudi Z, Tyagi I, Agarwal S, Maity A, et al. Modeling of competitive ultrasonic assisted removal of the dyes - methylene blue and Safranin-O using $\mathrm{Fe}_{3} \mathrm{O}_{4}$ nanoparticles. Chem Eng J. 2015;268:28-37. https:// doi.org/10.1016/j.cej.2014.12.090

Govindhan M, Adhikari BR, Chen A. Nanomaterials-based electrochemical detection of chemical contaminants. RSC Adv. 2014;4(109):63741-60. https:// doi.org/10.1039/C4RA10399H.

Goyal RN, Gupta VK, Chatterjee S. A sensitive voltammetric sensor for determination of synthetic corticosteroid triamcinolone, abused for doping. Biosensors Bioelectron. 2009a;24(12):3562-8. https://doi.org/10.1016/j.bios.2 009.05.016.

Goyal RN, Gupta VK, Chatterjee S. Fullerene-C60-modified edge plane pyrolytic graphite electrode for the determination of dexamethasone in pharmaceutical formulations and human biological fluids. Biosensors Bioelectronics. 2009b;24(6):1649-54. https://doi.org/10.1016/j.bios.2008.08 024.

Goyal RN, Gupta VK, Sangal A, Bachheti N. Voltammetric determination of uric acid at a Fullerene-C60-modified glassy carbon electrode. Electroanalysis. 2005;17(24):2217-23. https://doi.org/10.1002/elan.200503353.

Gupta VK, Goyal RN, Sharma RA. Comparative studies of neodymium (III)-selective PVC membrane sensors. Anal Chim Acta. 2009;647(1):66-71. https://doi.org/1 0.1016/j.aca.2009.05.031.

Gupta VK, Kumar S, Singh R, Singh LP, Shoora SK, Sethi B. Cadmium (II) ion sensing through p-tert-butyl calix[6]arene based potentiometric sensor. J Mol Liq. 2014a;195:65-8. https://doi.org/10.1016/j.molliq.2014.02.001.

Gupta VK, Maleh HK, Sadegh R. Simultaneous determination of hydroxylamine, phenol and sulfite in water and waste water samples using a voltammetric nanosensor. Int J Electrochem Sci. 2015a;10:303-16.

Gupta VK, Mergu N, Kumawat LK, Singh AK. A reversible fluorescence "off-on-off" sensor for sequential detection of aluminum and acetate/fluoride ions. Talanta. 2015b;144:80-9. https://doi.org/10.1016/j.talanta.2015.05.053.
Gupta VK, Mergu N, Kumawat LK, Singh AK. Selective naked-eye detection of Magnesium (II) ions using a coumarin-derived fluorescent probe. Sens Actuators B. 2015c;207:216-23. https://doi.org/10.1016/j.snb.2014.10.044.

Gupta VK, Nayak A, Agarwal S, Tyagi I. Potential of activated carbon from waste rubber tire for the adsorption of phenolics: effect of pre-treatment conditions. J Colloid Interface Sci. 2014b;417:420-30. https://doi.org/10.1016/j. jcis.2013.11.067.

Gupta VK, Singh AK, Kumawat LK. Thiazole Schiff base turn-on fluorescent chemosensor for $\mathrm{Al}^{3+}$ ion. Sens Actuators B. 2014c;195:98-108. https://doi. org/10.1016/j.snb.2013.12.092.

Gupta VK, Singh LP, Singh R, Upadhyay N, Kaur SP, Sethi B. A novel copper (II) selective sensor based on dimethyl 4, 4' (o-phenylene) bis(3-thioallophanate) in PVC matrix. J Mol Liq. 2012;174:11-6. https://doi.org/10.1016/j.molliq.2012. 07.016.

Gupta VK, Yola ML, Ozaltın N, Atar N, Ustundag Z, Uzun L. Molecular imprinted polypyrrole modified glassy carbon electrode for the determination of tobramycin. Electrochim Acta. 2013;112:37-43. https://doi.org/10.1016/j.electa cta.2013.08.132.

Han $H$, Yang $Y$, Zhang R, Brekhna B. Factors and paths of transformation and upgradation of chemical industry in Shandong, China. Sustainability. 2020; 12(8):3443. https://doi.org/10.3390/su12083443.

Harisha KV, Swamy BEK, Ebenso EE. Poly (glycine) modified carbon paste electrode for simultaneous determination of catechol and hydroquinone: a voltammetric study. J Electroanal Chem. 2018;823:730-6. https://doi.org/10.1 016/j.jelechem.2018.07.021.

He J, Qiu R, Li W, Xing S, Song Z, Li Q, et al. A voltammetric sensor based on eosin $Y$ film modified glassy carbon electrode for simultaneous determination of hydroquinone and catechol. Anal Methods. 2014;6(16): 6494-503. https://doi.org/10.1039/C4AY00575A.

He Q, Liu J, Feng J, Wu Y, Tian Y, Li G, et al. Sensitive voltammetric sensor for tryptophan detection by using polyvinylpyrrolidone functionalized graphene/GCE. Nanomaterials. 2020;10(1):125. https://doi.org/10.3390/nano1 0010125.

Hu F, Chen S, Wang C, Yuan R, Yuan D, Wang C. Study on the application of reduced graphene oxide and multiwall carbon nanotubes hybrid materials for simultaneous determination of catechol, hydroquinone, $\mathrm{p}$-cresol and nitrite. Anal Chim Acta. 2012;724:40-6. https://doi.org/10.1016/j.aca.2012.02.037.

Hung CM, Huang CP, Chen SK, Chen CW, Dong CD. Electrochemical analysis of naproxen in water using poly(L-serine)-modified glassy carbon electrode. Chemosphere. 2020;254:126686. https://doi.org/10.1016/j.chemosphere.202 0.126686 .

Jerez-Masaquiza MD, Fernández L, González G, Montero-Jiménez M, EspinozaMontero PJ. Electrochemical sensor based on Prussian blue electrochemically deposited at $\mathrm{ZrO}_{2}$ doped carbon nanotubes glassy carbon modified electrode. Nanomaterials. 2020;10(7):1328. https://doi.org/10.3390/nano1 0071328.

Karthikeyan S, Gupta VK, Boopathy R, Titus A, Sekaran G. A new approach for the degradation of high concentration of aromatic amine by heterocatalytic Fenton oxidation: Kinetic and spectroscopic studies. J Mol Liq. 2012;173:15363. https://doi.org/10.1016/j.molliq.2012.06.022.

Kumar AA, Swamy BEK, Ganesh PS, Rani TS, Reddy GV. Voltammetric determination of catechol and hydroquinone at poly(niacinamide) modified glassy carbon electrode. J Electroanal Chem. 2017;799:505-11. https://doi. org/10.1016/j.jelechem.2017.06.026.

Kumar AA, Swamy BEK, Rani TS, Ganesh PS, Raj YP. Voltammetric determination of catechol and hydroquinone at poly(murexide) modified glassy carbon electrode. Mater Sci Eng C. 2019;98:746-52. https://doi.org/10.1016/j.msec.2 018.12.055.

Lai T, Cai W, Dai W, Ye J. Easy processing laser reduced graphene: a green and fast sensing platform for hydroquinone and catechol simultaneous determination. Electrochim Acta. 2014;138:48-55. https://doi.org/10.1016/j. electacta.2014.06.070

Li D, Luo L, Pang Z, Ding L, Wang Q, Ke H, et al. Novel phenolic biosensor based on a magnetic polydopamine laccase-nickel nanoparticle loaded carbon nanofiber composite. ACS Appl mater interfaces. 2014;6(7):5144-51. https:// doi.org/10.1021/am500375n.

Li M, Ni F, Wang Y, Xu S, Zhang D, Chen S, et al. Sensitive and facile determination of catechol and hydroquinone simultaneously under coexistence of resorcinol with a $\mathrm{Zn} / \mathrm{Al}$ layered double hydroxide film modified glassy carbon electrode. Electroanal. 2009;21(13):1521-6. https://doi. org/10.1002/elan.200804573. 
Li SJ, Qiana C, Wang K, Hua BY, Wang FB, Sheng ZH, et al. Application of thermally reduced graphene oxide modified electrode in simultaneous determination of dihydroxybenzene isomers. Sens Actuat B. 2012;174:441-8. https://doi.org/10.1016/j.snb.2012.08.070.

Maleh HK, Javazmi FT, Atar N, Yola ML, Gupta VK, Ensafi AA. A Novel DNA biosensor based on a pencil graphite electrode modified with polypyrrole/ functionalized multiwalled carbon nanotubes for determination of 6mercaptopurine anticancer drug. Ind Eng Chem Res. 2015;54:14:3634-9. https://doi.org/10.1021/ie504438z.

Mansour AC, Samira B, Ghadamali B, Nasser G, Amir HM. Application of allura red in the construction of a novel amperometric flow sensor for the automatic determination of hydroquinone and catechol using a two-line flow injection manifold with a single-sensor/double-pulse amperometric detection. Meas Sci Technol. 2019;30(2):025801. https://doi.org/10.1088/1361-6501/aaf4e4.

Mesa JAG, Mateos R. Direct automatic determination of bitterness and total phenolic compounds in virgin olive oil using a pH-based flow-injection analysis system. J Agric Food Chem. 2007;55(10):3863-8. https://doi.org/10.1 021/jf070235v.

Minta D, Moyseowicz A, Gryglewicz S, Gryglewicz G. A promising electrochemical platform for dopamine and uric acid detection based on a polyaniline/iron oxide-tin oxide/reduced graphene oxide ternary composite. Molecules. 2020; 25(24):5869. https://doi.org/10.3390/molecules25245869.

Mulyasuryani A, Tjahjanto RT, Andawiyah R. Simultaneous voltammetric detection of acetaminophen and caffeine base on cassava starch- $\mathrm{Fe}_{3} \mathrm{O}_{4}$ nanoparticles modified glassy carbon electrode. Chemosensors. 2019;7(4):49. https://doi. org/10.3390/chemosensors7040049.

Nagaraja P, Vasantha RA, Sunitha KR. A new sensitive and selective spectrophotometric method for the determination of catechol derivatives and its pharmaceutical preparations. J Pharm Biomed Anal. 2001;25(3-4):41724. https://doi.org/10.1016/S0731-7085(00)00504-5.

Peng J, Gao ZN. Influence of micelles on the electrochemical behaviors of catecho and hydroquinone and their simultaneous determination. Anal Bioanal Chem. 2006;384(7-8):1525-32. https://doi.org/10.1007/s00216-006-0329-1.

Phal S, Shimizu K, Mwanza D, Mashazi P, Shchukarev A, Tesfalidet S. Electrografting of 4-carboxybenzenediazonium on glassy carbon electrode: the effect of concentration on the formation of mono and multilayers. Molecules. 2020;25(19):4575. https://doi.org/10.3390/molecules25194575.

Pliuta K, Chebotarev A, Pliuta A, Snigur D. Voltammetric determination of allura red $A C$ onto carbone-paste electrode modified by silica with embedded cetylpyridinium chloride. Electroanal. 2020;32:1-7. https://doi.org/10.1002/ela n.202060367.

Qi HL, Zhang CX. Simultaneous determination of hydroquinone and catechol at a glassy carbon electrode modified with multiwall carbon nanotubes. Electroanal. 2005;17(10):832-8. https://doi.org/10.1002/elan.200403150.

Robati D, Mirza B, Rajabi M, Moradi O, Tyagi I, Agarwal S, et al. Removal of hazardous dyes-BR 12 and methyl orange using graphene oxide as an adsorbent from aqueous phase. Chem Eng J. 2016;284:687-97. https://doi. org/10.1016/j.cej.2015.08.131.

Saravanan R, Joicy S, Gupta VK, Narayanan V, Stephen A. Visible light induced degradation of methylene blue using $\mathrm{CeO} 2 \mathrm{~N} 2 \mathrm{O} 5$ and $\mathrm{CeO} 2 / \mathrm{CuO}$ catalysts. Mater Sci Eng C. 2013a;33(8):4725-31. https://doi.org/10.1016/j.msec.2013.07.034.

Saravanan R, Karthikeyan N, Gupta VK, Thirumal E, Thangadurai P, Narayanan V, et al. $\mathrm{ZnO} / \mathrm{Ag}$ nanocomposite: an efficient catalyst for degradation studies of textile effluents under visible light. Mater Sci Eng C. 2013b;33(4):2235-44. https://doi.org/10.1016/j.msec.2013.01.046.

Saravanan R, Khan MM, Gupta VK, Mosquera E, Gracia E, Narayanan V, et al. ZnO/ $\mathrm{Ag} / \mathrm{CdO}$ nanocomposite for visible light-induced photocatalytic degradation of industrial textile effluents. J Colloid Interface Sci. 2015b;452:126-33. https:// doi.org/10.1016/j.jcis.2015.04.035.

Saravanan R, Thirumal E, Gupta VK, Narayanan V, Stephen A. The photocatalytic activity of $\mathrm{ZnO}$ prepared by simple thermal decomposition method at various temperatures. J Mol Liq. 2013c;177:394-401. https://doi.org/10.1016/j. molliq.2012.10.018.

Schmid A, Hollmann F, Park JB, Buhler B. The use of enzymes in the chemical industry in Europe. Curr Opin Biotechnol. 2002;13(4):359-66. https://doi.org/1 0.1016/S0958-1669(02)00336-1.

Shen Y, Rao D, Sheng D, Zheng J. Simultaneous voltammetric determination of hydroquinone and catechol by using a glassy carbon electrode modified with carboxy-functionalized carbon nanotubes in a chitosan matrix and decorated with gold nanoparticles. Microchim Acta. 2017;184(9):3591-601. https://doi.org/10.1007/s00604-017-2392-z.
Si W, Lei W, Zhang Y, Xia M, Wang F, Hao Q. Electrodeposition of graphene oxide doped poly(3,4-ethylenedioxythiophene) film and its electrochemical sensing of catechol and hydroquinone. Electrochim Acta. 2012;85:295-301. https:// doi.org/10.1016/j.electacta.2012.08.099.

Song D, Xia J, Zhang F, Bi S, Xiang W, Wang Z, et al. Multiwall carbon nanotubespoly(diallyldimethylammonium chloride)-graphene hybrid composite film for simultaneous determination of catechol and hydroquinone. Sens Actuators B. 2015;206:111-8. https://doi.org/10.1016/j.snb.2014.08.084.

Srivastava SK, Gupta VK, Jain S. A PVC-based benzo-15-crown-5 membrane sensor for cadmium. Electroanalysis. 1996;8(10):938-40. https://doi.org/10.1002/ela n.1140081017.

Steven CW. Technology vision 2020: The U.S. chemical industry. Stud Environ Sci. 1998;72:915-21. https://doi.org/10.1016/S0166-1116(98)80054-X.

Sukanya, Swamy BEK, Shashikumara JK. Poly (benzydamine) sensor for electrochemical resolution of catecholand hydroquinone. Mater Sci Energy Technol. 2020;3:640-7. https://doi.org/10.1016/j.mset.2020.06.009.

Sun YG, Cui H, Li YH, Lin XQ. Determination of some catechol derivatives by a flow injection electro chemiluminescent inhibition method. Talanta. 2000; 53(3):661-6. https://doi.org/10.1016/S0039-9140(00)00550-6.

Umasankar Y, Periasamy AP, Chen SM. Electrocatalysis and simultaneous determination of catechol and quinol by poly(malachite green) coated multiwalled carbon nanotube film. Anal Biochem. 2011;411(1):71-9. https:// doi.org/10.1016/j.ab.2010.12.002.

Vilian ATE, Chen SM, Huang LH, Ali MA, Al-Hemaid FMA. Simultaneous determination of catechol and hydroquinone using aPt/ZrO2-RGO/GCE composite modified glassy carbon electrode. Electrochim Acta. 2014;125: 503-9. https://doi.org/10.1016/j.electacta.2014.01.092.

Wang J. Analytical electrochemistry. New York: VCH Publishers; 1994.

Wang L, Huang P, Bai J, Wang H, Zhang L, Zhao Y. Simultaneous electrochemical determination of phenol isomers in binary mixtures at a poly(phenylalanine) modified glassy carbon electrode. Int J Electrochem Sci. 2006;1:403-13.

Wang L, Huang P, Bai J, Wang H, Zhang L, Zhao Y. Direct simultaneous electrochemical determination of hydroquinone and catechol at a poly(glutamic acid) modified glassy carbon electrode. Int J Electrochem Sci. 2007a;2:123-32.

Wang L, Huang P, Wang H, Bai J, Zhang L, Zhao Y. Electrocatalytic response of hydroquinone and catechol at polyglycine modified glassy carbon electrode. Int J Electrochem Sci. 2007b;2:216-25.

Wang L, Huang PF, Bai JY, Wang HJ, Zhang LY, Zhao YQ. Covalent modification of a glassy carbon electrode with penicillamine for simultaneous determination of hydroquinone and catechol. Microchim Acta. 2007c;158(12):151-7. https://doi.org/10.1007/s00604-006-0703-X.

Wang $Y$, Hasebe $Y$. Acridine orange-induced signal enhancement effect of tyrosinase-immobilized carbon-felt-based flow biosensor for highly sensitive detection of monophenolic compounds. Anal Bioanal chem. 2011;399(3): 1151-62. https://doi.org/10.1007/s00216-010-4369-1.

Watanabe K, Sugiyama K, Komatsu S, Yoshida K, Ono T, Fujimura T, et al. Voltammetric $\mathrm{pH}$ measurements using azure a-containing layer-by-layer film immobilized electrodes. Polymers. 2020;12(10):2328. https://doi.org/10.3390/ polym12102328.

Xia Y, Wang K, Shi Y, Gui X, Lv C, Tao H. Reduced graphene oxide cross-linked Lcysteine modified glassy carbon electrode for detection of environmental pollutant of hydroquinone. Flat chem. 2021;25:100214. https://doi.org/10.101 6/j.flatc.2020.100214.

Xiao H, Wang W, Pi S, Cheng Y, Xie Q. Pyridine-2-sulfonic (or carboxylic) acid modified glassy carbon electrode for anodic stripping voltammetry analysis of $\mathrm{Cd}^{2+}$ and $\mathrm{Pb}^{2+}$. Anal Chim Acta. 2020;1135:20-8. https://doi.org/10.1016/j.a ca.2020.08.024.

Xu G, Tang B, Jing S, Tao J. Simultaneous determination of hydroquinone, catechol and resorcinol at poly(3-thiophenemalonic acid) modified glassy carbon electrode. Int J Electrochem Sci. 2015;10:10659-67.

Yang P, Zhu Q, Chen Y, Wang F. Simultaneous determination of hydroquinone and catechol using poly(p-aminobenzoic acid) modified glassy carbon electrode. J Appl Polym Sci. 2009;113(5):2881-6. https://doi.org/10.1002/app.30393.

Yin H, Zhang Q, Zhou T, Ma Q, Liu T, Zhu L, et al. Electrochemical behavior of catechol, resorcinol and hydroquinone at graphene-chitosan composite film modified glassy carbon electrode and their simultaneous determination in water samples. Electrochim Acta. 2011;56:2748-53. https://doi.org/10.1016/j. electacta.2010.12.060.

Yola ML, Gupta VK, Eren T, Sen AE, Atar N. A novel electro analytical nanosensor based on graphene oxide/silver nanoparticles for simultaneous 
determination of quercetin and morin. Electrochim Acta. 2014;120:204-11. https://doi.org/10.1016/j.electacta.2013.12.086.

Zhang M, Ge C, Jin Y, Hu L, Mo H, Li X, et al. Sensitive and simultaneous determination of hydroquinone and catechol in water using an anodized glassy carbon electrode with polymerized 2-(phenylazo) chromotropic acid. J Chem. 2019;2327064:10. https://doi.org/10.1155/2019/2327064.

Zhang Y, Sun R, Luo B, Wang L. Boron-doped graphene as high-performance electrocatalyst for the simultaneously electrochemical determination of hydroquinone and catechol. Electrochim Acta. 2015;156:228-34. https://doi. org/10.1016/j.electacta.2014.12.156.

Zhang Y, Zheng JB. Comparative investigation on electrochemical behavior of hydroquinone at carbon ionic liquid electrode, ionic liquid modified carbon paste electrode and carbon paste electrode. Electrochim Acta. 2007;52(25): 7210-6. https://doi.org/10.1016/j.electacta.2007.05.039.

Zhao DM, Zhang XH, Feng $\sqcup$, Jia L, Wang SF. Simultaneous determination of hydroquinone and catechol at PASA/MWNTs composite film modified glassy carbon electrode. Colloids Surf B. 2009;74:317-21. https://doi.org/10.1016/j. colsurfb.2009.07.044.

Zheng LZ, Xiong L, Li YD, Xu JP, Kang XW, Zou ZJ, et al. Facile preparation of polydopamine-reduced graphene oxide nanocomposite and its electrochemical application in simultaneous determination of hydroquinone and catechol. Sens Actuators B. 2013;177:344-9. https://doi.org/10.1016/j. snb.2012.11.006.

\section{Publisher's Note}

Springer Nature remains neutral with regard to jurisdictional claims in published maps and institutional affiliations.

\section{Submit your manuscript to a SpringerOpen ${ }^{\circ}$ journal and benefit from:}

- Convenient online submission

- Rigorous peer review

- Open access: articles freely available online

High visibility within the field

- Retaining the copyright to your article

Submit your next manuscript at $\boldsymbol{\nabla}$ springeropen.com 